Etsuko Yamada*

\title{
Investigating the roles of first language (L1) speakers in lingua franca communication in multicultural classrooms: a case study of Japanese as a Lingua Franca (JLF)
}

https://doi.org/10.1515/jelf-2021-2057

\begin{abstract}
In the Expanding Circle (i.e. countries where English is traditionally learned as a "foreign language"), the concept lingua franca cannot be limited to English. Conducted in a Japanese university, this study reports on the perceptions of verbal behaviours by students in multicultural courses where international and Japanese students studied together. These behaviours were analysed and the findings from English medium instruction courses and those of Japanese-medium instruction (JMI) courses were compared. Then, further analysis centred on JMI courses to explore the roles of Japanese L1 speakers in the co-construction of Japanese as a lingua franca with a focus on cognitive and psychological, rather than linguistic, perspectives. Rapport building, accommodation strategies, often initiated by L1 Japanese speakers, and the spontaneous interactions of second language (L2) speakers in discussions, are assumed to have been the keys to more inclusive interactions in JMI courses. The findings emphasize the importance of students' attitudes and imply that intercultural education in the context, including both L1 speakers and L2 speakers, will have potential to foster effective lingua franca users.
\end{abstract}

Keywords: classroom common language; intercultural education; Japanese as a lingua franca; L1 speakers; lingua franca; multicultural classroom context

要旨: 当研究は第一言語話者の lingua franca (LF) における役割を明らかにする ことを目的とし、日本の大学の留学生と日本の学生が共に学ぶ多文化クラス

で、学生の言語行動に関する認識についての実証研究を実施した。English as a lingua franca (ELF) を使用したクラスと Japanese as a lingua franca (JLF) を使 用としたクラスとを比較した上で、JLFにおける第一言語話者である日本の学 生に焦点を当てて詳細な分析、考察を行った。日本語第一言語話者が主体のラ ポール形成や言語調整行動、討論への第二言語話者の積極的な参加などが、

\footnotetext{
*Corresponding author: Etsuko Yamada, Research Faculty of Media and Communication, Hokkaido University, Sapporo, Hokkaido, Japan, E-mail: etsukoyamada91@gmail.com. https://orcid.org/0000-0002-7673-5615
} 
JLF でのインクルーシブなコミュニケーションにつながったと考えられた。第 一言語話者、第二言語話者の双方を含めたコンテクストにおいて、言語的スキ ルよりも心的態度の醸成に重点を置いた異文化間教育が、効力のある LF 使用 者の育成の可能性として重視されるであろう。

キーワード: クラス内共通言語、異文化間教育、リンガフランカ日本語、第一 言語話者、リンガフランカ、多文化クラスコンテクスト

\section{Introduction}

With the advance of globalization, the internationalization of higher education worldwide has become widespread policy. The number of classrooms with students from a variety of linguistic and cultural backgrounds has thus increased including in Japan in recent years - raising important new questions in pedagogy and research. How to manage a language of instruction, that is, to co-construct a common language and shared culture for the classroom community, has become a significant challenge. The increasing use of English as a shared language among English second language (L2) speakers in international business, diplomatic, and academic contexts - including classrooms - has led to the development of the concept of English as a lingua franca (ELF). In fact, the concept can also be extended to any language in any space where both first language (L1) speakers and L2 speakers need to co-construct a common language for communication, as I shall demonstrate below.

An empirical study was conducted in a state university in Japan in multicultural courses $^{1}$ where international and Japanese students study together. Here, I report some of the findings of a project on lingua franca communication in multicultural courses offered in two different languages of instruction: English medium instruction (EMI) and Japanese medium instruction (JMI). The purpose of this project was to compare the different roles of Japanese students as L2 speakers in an ELF situation in EMI courses, and L1 speakers in a Japanese as a lingua franca (JLF) situation in JMI courses (Yamada 2019a, 2019b). First, I shall provide a brief overview of the comparative analysis of Japanese students in both courses and then the main focus will be on JMI courses and L1 speaker roles in JLF communication.

1 This term and its concept may not be common in other countries. There are several other terms for this type of courses in Japanese, such as kokusai kyoshu kurasu 'international cooperative class/ course' and kokusai koryu kurasu 'international exchange class/course', etc. This article adopts "multicultural courses," an English equivalent to the most widely used term, tabunka kurasu, on the ground that the result of search in "Cinii Articles" (article database published in Japanese, accessed 20 December 2020) indicated 33 article titles include "tabunka-kurasu," while titles using other terms were few. More detailed background of multicultural courses is given in Section 2. 


\section{The language context of international students and multicultural courses in higher education in Japan}

Various types of international students currently visit Japan for a range of time periods, from long-term studies to obtain degrees (at both undergraduate and postgraduate research levels) to temporary sojourns, such as university exchange programmes and study experiences at language institutes. Since the 1980s, the Japanese government has intensely promoted the increase of international students. $^{2}$ In 2019, 228,403 international students enrolled in Japanese universities (JASSO 2020). Reflecting on the governmental policies and the enhancement of the internationalization of higher education, most Japanese universities have promoted the recruitment of international students.

The courses at the undergraduate level in Japanese universities are usually offered in Japanese, ${ }^{3}$ and international students who follow the same four-year bachelor degree courses as Japanese students do are usually required to have a high proficiency level of Japanese for admission (JASSO 2019). In the author's university, one of the largest state universities in Japan with 12 schools of various disciplines, there were a total of 18,713 students in 2019 (hereafter statistics are from Hokkaido University [2019]). The number of international students in the four-year undergraduate tracks (EMI and JMI) is approximately $0.8 \%(n=173)$ of the total number of international students $(n=2,268)$. While at postgraduate levels, Japanese language is usually required in humanities and social sciences, English is commonly used in science. Nearly $80 \%(n=1,746)$ of the total number of international students are postgraduate level and approximately $32 \%(n=565)$ of international postgraduate students are in humanities and social sciences, while the rest are in science.

About 11\% $(n=253)$ of international students are from 196 overseas partner institutions by exchange agreement on study abroad to Japan for less than one year (short-term student exchange programmes), which corresponds to their third-year undergraduate curriculum of their home institution. They are divided into two

2 In 1983, a new policy to raise the intake of international students to 100,000 by the year 2000 was announced by then Prime Minister as "Ryugakusei Ukeire Jyumanin Keikaku" ['Plan for 100,000 exchange students'] (MEXT 2020a). This target was achieved in 2002 (Immigration Services Agency of Japan 2003), with a further increase announced in 2008 to reach 300,000 by 2020 as "Ryugakusei Ukeire Sanjyumanin Keikaku” ['Plan for 300,000 exchange students'] (MEXT 2008). This target was also achieved, with 336,847 international students at the end of June 2019 (e-Stat 2020).

3 There are a few exceptional universities in Japan which offer most courses in English: Akita International University (98\%), Ritsumeikan Asia Pacific University (88.9\%) (JASSO 2019). 
groups: EMI group (approximately 200 students) and JMI group (approximately 50 students). The minimum language requirement for the EMI group is a score of 79 in TOEFL iBT (Test of English as a Foreign Language Internet-based Test) or 6.5 in IELTS (International English Language Testing System). For the JMI group, JLPT (Japanese Language Proficiency Test) ${ }^{4}$ of N3 level is required. These international exchange students are the main targets of multicultural courses. These courses are offered as credited elective courses. For Japanese students, they are in the elective subject category of general education and offered to any undergraduate student. Only a few of them, however, take these courses.

The short-term student exchange programme curriculums in Japan typically consist of Japanese language courses and introduction to Japanese culture and society courses in English and/or Japanese. Because of these curriculums, international exchange students have usually been taught separately from Japanese students (with exceptions in a few universities, as mentioned in note 3). Although this tendency to separate international exchange students from Japanese students still exists, integration of both students has gradually been introduced since the 1990s. ${ }^{5}$ Especially at advanced levels, Japanese language courses often plan sessions inviting Japanese L1 students to enhance Japanese L2 learners' "authentic" interactions in Japanese. Sessions on Japanese culture and society taught in English are gradually being opened to Japanese students and are seen as good opportunities for the expansion of EMI for them.

The content-based and non-language teaching courses, which are called multicultural courses, where international and Japanese students study together, were developed from these integrated classes. The medium of instruction commonly used in these courses is either English, Japanese or a bilingual mix of English and Japanese - and there are no established language policies in general. Whether in English or Japanese, having both L1 speakers and L2 speakers in the same classroom requires the construction of a common means of interaction, i.e., a lingua franca. As previously mentioned, the minimum language requirement for international students is set as one of the conditions for admission. For Japanese students, the minimum language requirement is set by the individual course instructor and is usually above B1 level in the CEFR (Council of Europe 2001). However, it is often the case that students with various oral proficiency levels are present among the L2 speakers in multicultural courses. In contrast to the lecture style for large numbers of students in standard content-based courses at the undergraduate and postgraduate levels in Japan, these

4 JLPT N3 level is almost equivalent to A2-B1 level in Common European Framework of Reference for Languages (CEFR) (Council of Europe 2001). N2 level is B2-C1 level in CEFR.

5 It is difficult to identify accurate sources of statistics on this information, but there are many articles written in Japanese on this matter. (See also footnote 1 above.) 
multicultural courses are small and usually introduce active-learning and problem/ project-based learning (PBL) to encourage more interactions between the students.

Over one hundred EMI multicultural courses in a wide range of disciplines are offered each year. ${ }^{6}$ Approximately $60 \%$ of the instructors are international professors and the rest are Japanese professors, typically with some years of experience overseas. Around 15 JMI multicultural courses are offered each year and most of the instructors are Japanese as a foreign language professors. In the author's university, there is no specific educational policy on these multicultural courses. But it is one of the 13 universities selected for "Top Global University Project” in 2014, aiming to be ranked among the world's top 100 universities in 10 years. And under the roof of this national initiative, the increase of EMI courses as well as the employment of international professors and the intake of international students are all intertwined (Hokkaido University 2020; MEXT 2020b).

\section{Lingua franca and L1 speakers}

Before the appearance of ELF as a research paradigm, English already started to establish its position as the most frequently and widely used international common language with the increase of population mobility and communication beyond national borders, often referred to previously as "English as an international language (EIL)" or "English as an international auxiliary language (EIAL)"7 as defined by Smith (1976). However, it has occasionally been questioned whether English is automatically accepted as an international common language, because the English used by "native speakers" often carried a negative image associated with linguistic imperialism of the British Empire and the United States of America (Philipson 1992). This linguistic hegemony was the target of criticism as neo-colonization through language. As a result, "EIL including native speakers" may be associated with the unequal power balance between "accurate" native speakers and "inferior" nonnative speakers. The dilemma already appeared in the development of EIL.

At the early stages of its development, the concept of ELF was sometimes (mis) interpreted as English without the presence of English L1 speakers (on this misinterpretation, see Jenkins [2007, 2015]). The definition that Firth (1996) provided clearly excludes L1 speakers: "English is used as a 'lingua franca' - a 'contact language' between persons who share neither a common native tongue nor a common

6 Apart from these regular multicultural courses in two-semester system, a quarter length summer intensive course for the students of exchange partner institutions is held every year, and nearly 150 EMI multicultural courses are offered.

$7 \mathrm{EIL} / \mathrm{EIAL}$ is regarded as basically different from ELF by much research in terms that it concerns varieties of English as in the World Englishes paradigm (Baker 2015b; Widdowson 2018). 
(national) culture, and for whom English is the chosen foreign language of communication" (Firth 1996: 240, italics in original). The demand for the international use of English came mainly from English L2 speakers due to the increase in globalization and international contacts and it can be considered natural that English without English L1 speakers was the more common context. The origin of the term lingua franca has been traced to a pidgin used in the Mediterranean area from the fifteenth to the nineteenth century, i.e., a hybrid language of Spanish, French, Portuguese, Arabic, Turkish, and Greek. This pidgin was used as a common language among traders and was a mother tongue to none of them (Gnutzmann 2017; Haberland 2011; Jenkins 2007). A common language where none of the speakers use the language as L1 has the advantage that all the participants have equal status.

The discussion of "with L1 speakers" or "without L1 speakers" has been summarized by Jenkins (2007, 2015). In addition to her initial definition of ELF as "a contact language among speakers from different first languages” (Jenkins 2007: 1), she later added (Jenkins 2015: 44) Seidlhofer's (2011) point: i.e., “Any use of English among speakers of different first languages for whom English is the communicative medium of choice, and often the only option" (Seidlhofer 2011: 7, italics in original).

Teaching learners to use English as a contact language has principally had to develop in educational settings where the classroom does not usually include English L1 speakers, except, in some cases, for the teacher. Much research on ELF has been undertaken which does not include English L1 speakers. But the discussion on the pedagogical implications for English L1 speaker roles in the early stage of EIAL by Smith (1983) can also be applied to ELF. Smith pointed out that there is much for L1 speakers to learn such as tolerance for different pronunciation patterns and sensitivity to the probability of misunderstanding and skills to deal with it. The need to educate L1 speakers has also been extensively pointed out by Jenkins (2011, 2012): i.e., ELF is not the same as English as a native language; therefore, ELF also needs to be acquired by L1 English speakers. Seidlhofer (2012) has made this point in principle by stating that all speakers of English(es) have to learn how to use ELF. Campbell et al. (1983) made the same point, and they seem to see this as a matter of training skills:

Two other important principles of EIL (English as an international language) follow from this view: (1) native speakers of English need training in the use of their own language in international settings, and (2) non-native speakers of English need training in the use of English not just with native speakers, but with non-native speakers, as well. (Campbell et al. 1983: 35-36)

Some studies have investigated how effectively English L1 speakers accommodate in lingua franca intercultural communications, with several having reported L1 speakers' shortcomings in managing ELF, with communication breakdowns found in several studies to be mainly caused by English L1 speakers (Henderson 2005; Jenkins 2011; Subtirelu and Lindemann 2016; Sweeney and Hua 2010). Phillipson (2003) makes the same point: 


\begin{abstract}
Native speakers have greater facility in speaking the language, but not necessarily greater sensitivity in using it appropriately. In many international fora, competent speakers of English as a second language are more comprehensible than native speakers, because they can be better at adjusting their language for people from different cultural and linguistic backgrounds. (Phillipson 2003: 167)
\end{abstract}

Kirkpatrick (2014) focuses on English used in the Asia-Pacific region as a specific case of English in non-Anglo cultural contexts, proposing six principles of a lingua franca approach in relation to ASEAN English. In one of these principles, he suggests "[l]ingua franca environments provide excellent learning environments for lingua franca speakers" (Kirkpatrick 2014: 30). Multicultural courses in Japanese universities described in this study provide similar opportunities, creating a natural necessity for lingua franca interaction. Therefore, an empirical study of multicultural courses was planned to investigate the issues of lingua franca education in a context including L1 speakers.

\title{
4 Lingua franca issues with other languages
}

Borghetti and Beaven (2017) point out that there are few academic studies dealing with lingua francas other than English, but lingua franca issues can arise in any language. However, Japan's sociolinguistic situation is quite different from the case of English-speaking countries. Compared with nation states that embraced their diverse ethnic origins from the early stages of their construction or historically had immigrants as part of their character, as in Singapore or Australia, Japanese society has not yet reached a stage where it can be described as multicultural to any consequential degree. Although there has been a substantial increase in foreign residents in the last several decades, the proportion of foreign residents in Japan overall at the end of 2019 was only $2.4 \%$ (approximately 2.9 million out of a total population of 123 million) (e-Stat 2020). A few areas have a relatively high population density of foreign residents, and awareness of a multicultural society has been raised to a certain extent there. However, the "one language-one culture" pair drawn from eighteenth-century nation-state ideologies (Borghetti and Beaven 2017: 223) is still held widely in Japanese society and remains unquestioned by the majority of the population.

In this context of the significance of ELF internationally and the particular case of ELF and JLF in Japan, multicultural courses in the author's university in Japan appear to be a good context for conducting education and research on lingua franca communication which includes L1 speakers. A certain number of L1 speaker students are always included in the classroom in both EMI courses and JMI courses, while their proportion has never been the majority of the class participants. This means that, in both courses, the lingua franca cannot be dominated by 
L1 speakers. Their presence makes the classroom situation correspond to the definitions of ELF by Jenkins and others discussed above.

\section{Research design}

In English as a foreign language classes in Japanese universities, Japanese undergraduate students are widely perceived to have "weak" English-speaking skills. Consequently, numerous studies have attempted to improve this situation (Cutrone and Beh 2018; Effiong 2016; Talandis and Stout 2015). In EMI multicultural courses, this perception is even more evident when contrasted with the behaviours of international students who are generally active in the classroom, although there are always a few exceptions. It has been pointed out that Japanese students are usually less active and can struggle with joining in meaningful interactions during discussions in EMI multicultural courses (Matsuta et al. 2001; Sakamoto 2013; Sato 2011; Watanabe et al. 2017). This observation is partly attributed to the lack of oral proficiency in English and a perceived foreign language anxiety among Japanese students, who tend not to have ever experienced using English in practical international contexts. However, the author's observations of how Japanese students behave as Japanese L1 speakers in JMI multicultural courses - where there are no foreign language obstacles for Japanese students - suggest the causes cannot be restricted to only these linguistic factors.

The data used in this study form part of a larger-scale project on multicultural courses. An ethnographic investigation of the student perceptions of verbal behaviours of Japanese students as L1 speakers in JMI courses in contrast with those as English L2 speakers in EMI courses was conducted (Yamada 2019a, 2019b). Some contributing factors of L1 speaker roles in the construction of a lingua franca were identified, and this study aims to further explore these. In JLF, it is easier to identify L1 speakers and the L1 speaker cohort is relatively homogeneous, unlike in ELF, where there is usually a wide range of English L1 speaker variations. Therefore, the role of L1 speaker in JLF was thought to be more visible than in ELF. To ensure a clear focus in research design, this study deals with the following research question:

How do Japanese L1 speakers play their L1 roles in the co-construction of JLF?

Hardly any other previous research in JLF in multicultural courses is available to build testable hypotheses on; therefore, this study is exploratory, applying a qualitative research methodology with a strong emphasis on the characteristics of a 
“natural setting” (Brinkmann and Kvale 2018; Flick 2018; Miles et al. 2020). A loose research design (Flick 2018; Miles et al. 2020) that selected all the related phenomena in naturally occurring data in the field was considered most appropriate for this research. In this ethnographic approach, it was anticipated that relevant phenomena in the setting that cannot be known in advance will be noticed as much as possible. Furthermore, collecting three different types of data as described below was undertaken to ensure data triangulation. Although the target group was Japanese students, data were also collected from international students in the anticipation that this might reveal behaviours noticed by international students that these Japanese students may not be conscious of.

\section{Data collection}

Three kinds of data were collected from the multicultural courses (three courses in EMI and two courses in JMI) from 2015 to 2018 where the author herself was the sole teacher. The data consist of the following:

a. Reflection notes which students were asked to submit at the end of each session (maximum 200-word length, the students could write anything, but in particular, what seemed to them to be most impressive in the session).

b. Final essay (minimum 1,000-word length) entitled "How your view on Japanese people or customs in Japan changed/did not change or developed after the critical investigation activities in the course".

c. Semi-structured group interviews performed after the end of the courses.

Data types (a) and (b) were assumed to present what appeared most striking to each student without letting him/her be conscious of what the author was investigating. These data were considered to be naturally occurring as they were course requirements for the students enrolled in the classes. The international and Japanese students were grouped separately for the interviews. The language in the course they were taking was used for interviews with international students, but Japanese student groups were always interviewed in Japanese whatever the course.

The ethical procedure established by the author's university was followed. First, permission for data collection was gained from the ethical committee of the university. The data collection procedure was then explained orally to all the students, including international students, with written supporting documents. The purpose of the research, confidentiality and anonymity, freedom of withdrawal from the study at any time without providing reasons, and no influence on academic activities were promised. Written consents were gained from all the students. 
Each course consisted of 15 sessions of 90 min once per week. The content was focused on critical thinking, which was developed by daily intercultural encounters. During the first seven sessions, some Japanese cultural concepts such as "work ethic", "courtesy", and "harmony" were topics for discussion. Afterwards, theories on critical thinking were introduced and the students tackled a group research project, including a survey on a topic of their choice under the general theme of Japanese conventions and concepts.

A total of 38 international $^{8}$ and 15 Japanese students in EMI courses, and 26 international and 19 Japanese students in JMI courses participated in this study. The international students came from all over the world, including East Asia, Southeast Asia, North and South America, Oceania, Africa, Europe, and the Middle East. Many countries were represented in both courses, with no majority group from any particular region. Genders were also well balanced among the students. Most international students were in the third year of their home universities, while many of the Japanese students were in the first or second year of undergraduate studies.

As detailed above in Section 2, there was a minimum language requirement for L2 speakers in both courses. The author also checked the L2 speakers' (approximately $90 \%$ of L2 students) oral proficiency level using the American Council on the Teaching of Foreign Languages Oral Proficiency Interview (ACTFL OPI) scale and confirmed that most L2 speakers reached at least intermediate-mid level of the OPI scale. ${ }^{9}$ The main activities in the classes are discussions. Oral proficiency is important in classroom interactions, but it cannot be properly measured by the general English test scores. In the analysis of unsuccessful interaction cases, the lack of oral skills and other non-linguistic factors need to be separated. Therefore the author decided to conduct the assessment on oral skills, as well. ACTFL OPI also seemed to be a suitable instrument as it does not simply judge speakers' oral proficiency according to native speaker norms. The qualification was developed for non-native speakers and the learning goals are not primarily defined in relation to native speakers. In my view, as the description of the highest level (distinguished) is defined for instance as "educated and articulate uses of the language" (ACTFL 2012), it is therefore compatible with an ELF perspective.

Apart from the difference of languages of instruction, both courses followed the same contents and materials including much use of illustration and diagrams to avoid heavily relying on written texts. Instructors were not allowed to control the

8 Eight English L1 speakers from Nigeria (4), UK (1), and USA (3) are included.

9 ACTFL OPI has four major levels: superior, advanced, intermediate and novice. Each major level is further divided. At advanced level, learners are able to form speech including paragraphs, while at intermediate level, they can manage to form sentences. At novice level, learners are not able to produce sentences (ACTFL 2012). The author is a certified ACTFL OPI tester (2016-2024). 
student enrolments; thus, the numbers of Japanese and international students in a classroom were often unbalanced. However, the students were divided into mixed groups of international and Japanese students for class activities, including five to six in each group. In general, a range of oral proficiency levels was always observed among L2 speakers. Japanese students without experience of having lived outside Japan tend to have relatively limited oral English skills, but a few students also had good oral skills despite not having been overseas.

\section{Data analysis}

First, all the three kinds of students' output data listed in Section 6 were carefully studied. Secondly, the descriptions consisting of a few to several sentences related to "student perceptions related to language awareness or verbal behaviours in the classrooms" were exclusively extracted from the whole data set. Then, these segments were grouped according to the content and code names and tagged for specific aspects of this theme. In all, 19 codes were established, which were then classified into five major groups, named "domains" according to the place or space in which the phenomenon happens: "Self-awareness" (five codes related to the students' awareness of their own language use), "Japanese students" (three codes describing Japanese students' verbal behaviours), "International students” (two codes describing international students' verbal behaviours), "Inside the group” (five codes describing interactions inside the group), and "Outside the classroom" (four codes mentioning the expanded possibilities of the current activities beyond the classroom). ATLAS.ti software for qualitative data analysis was used to organize the data.

In qualitative research, quantitative analysis should not be ignored, as argued by Sandelowski (2001) and Olson (2000). An overview in Table 1 provides a preliminary contrast between the characteristics of Japanese students' perceptions of verbal behaviours in multicultural courses with two different languages of instruction. It also presents the proportion out of the total segment number in each medium language group expressed by percentage (Yamada 2019a, 2019b).

The total number of segments in both EMI and JMI courses was 153, respectively, which was simply a coincidence. The total number from Japanese students was higher than the ones from international students in both courses (85.6\% in EMI courses and $60.1 \%$ in JMI courses). As the data are naturally occurring, it is assumed from these high rates that language issues were important in the minds of Japanese students, who appear to have had a more intense consciousness about this issue than did the international students. Here and below, the translations were performed by the author and are literal in nature to keep close to the original data. 


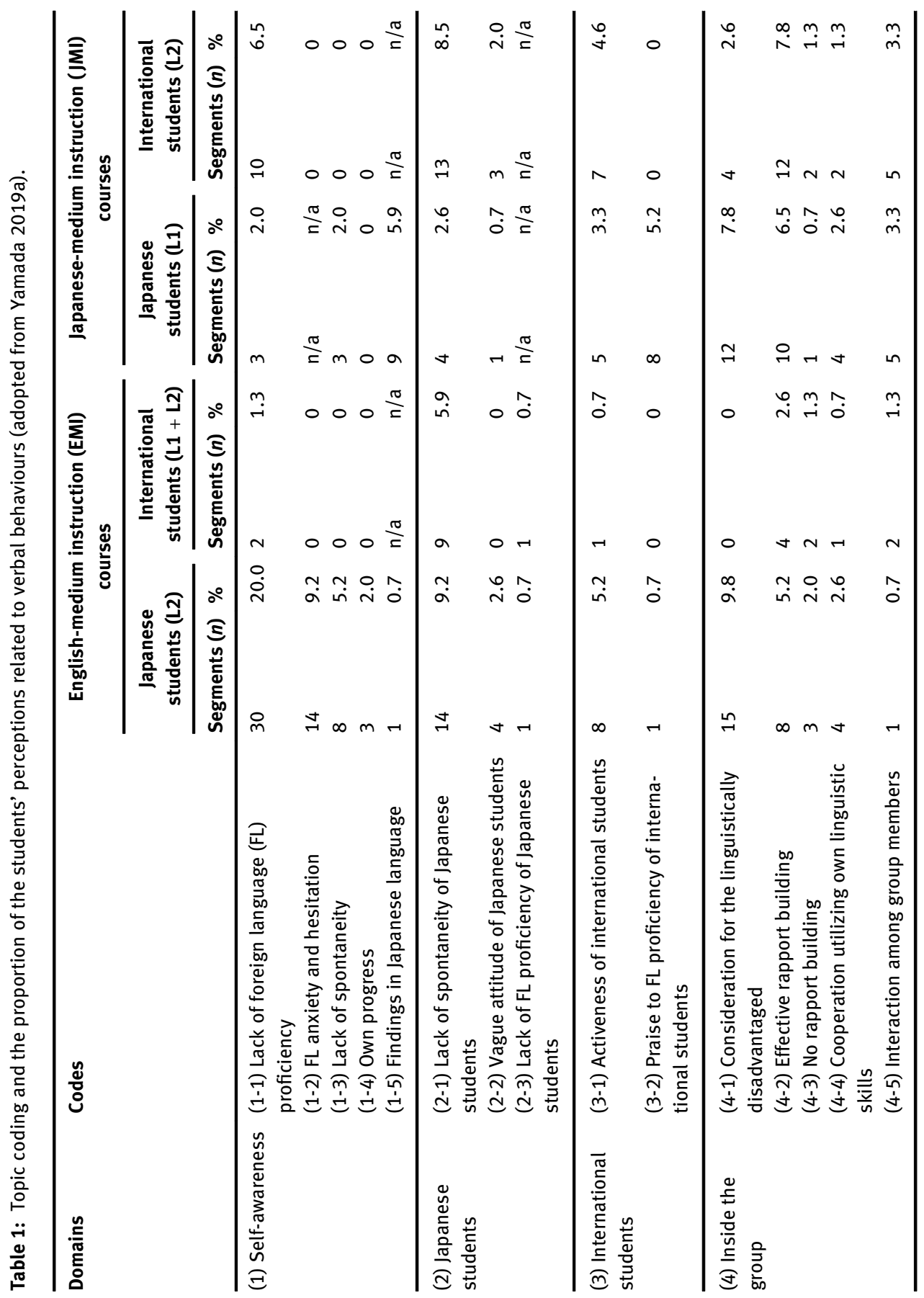




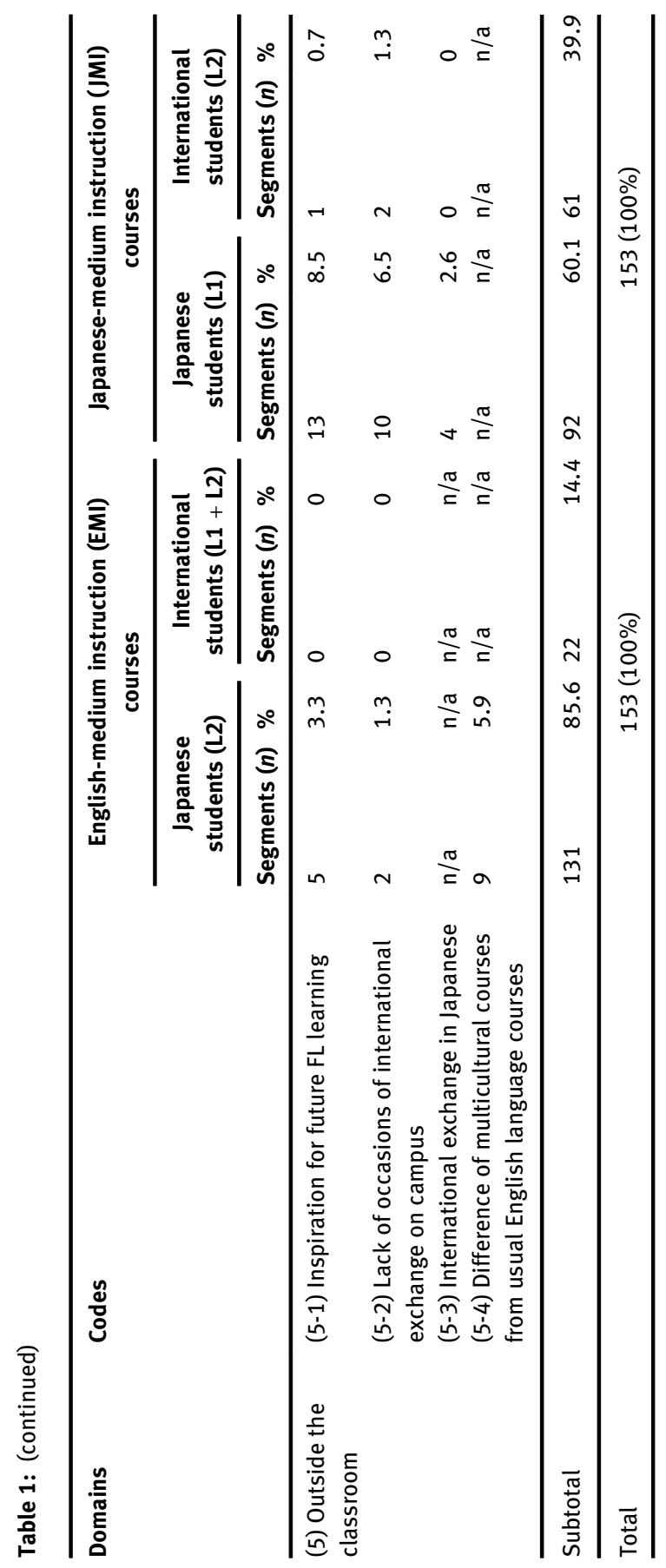




\subsection{Foreign language anxiety of Japanese students as $L 2$ speakers in EMI courses}

The analysis revealed the distinctive characteristics of Japanese students as English L2 speakers in ELF classes. The higher percentages expressed by Japanese students, i.e., $20.0 \%$ in "(1-1) lack of foreign language (FL) proficiency”, drew our attention first. This also corresponded to quite a lot of comments in the reflection notes in which participants report being ashamed of their own English language skills. They thought that it was their lack of English proficiency which caused their lack of spontaneity:

(1) The group discussions always make me feel I wish I could speak English more fluently. It makes me aware that my listening and speaking skills are not satisfactory because I recognize that quite often, I cannot say what I want to say in English well.

(Japanese student [L2]/EMI)

Some L2 speakers among the international students in both EMI and JMI courses also recognized their own perceived lack of L2 language skills, but the percentages of comments on this are lower, i.e., 1.3 and 6.5\% in EMI and in JMI courses, respectively, compared with the $20.0 \%$ mentioned above for Japanese students.

(2) Sometimes I could not understand English. I could not explain well. (International student [L2]/EMI)

(3) During the group works and discussions, I could not express myself well and I strongly recognized that my Japanese language skills are not yet satisfactory. (International student [L2]/JMI)

The next focus of analysis was on the higher proportion of 9.2\% in “(1-2) FL anxiety and hesitation" from Japanese students, which was associated with the above selfawareness phenomenon. What was salient among Japanese students as English L2 speakers was their anxiety and hesitation to speak up in English because they were worried about becoming troublesome in the classroom interactions. They just simply used a "let it pass strategy" (Firth 1996) or refrained from stopping the discussion:

(4) If it was an utterance to me only, it was not difficult for me to say that I did not understand some parts. But if it was a group interaction, I did not want to interrupt the flow of discussion if all others understood it. I just let it pass and pretended that I did not need any help.

(Japanese student [L2]/EMI) 
(5) The discussions of my group were flowing smoothly. I did not want to stop it by asking about what I did not understand.

(Japanese student [L2]/EMI)

However, this kind of data did not appear in international students as L2 speakers in both courses because their own recognition of their lack of proficiency in foreign language skills did not necessarily lead to hesitation and lack of spontaneity.

Although the above results may appear to confirm the conventional perception of Japanese students, it is important to examine more closely whether their hesitation to speak up is entirely attributable to their lack of oral proficiency. As stated earlier, the author had checked that most L2 speakers in both languages met intermediate-mid level of the ACTFL OPI scale. Actually, both cohorts did encompass a range of linguistic levels, from students with distinguished level skills for L2 speakers to students with relatively limited foreign language skills who have just passed the course language requirement. Although many Japanese students in the study had intense self-awareness of their perceived lack of language skills, few international students referred to this as evident in "(2-3) lack of FL proficiency of Japanese students" (as shown in Table 1). Although it is true to a certain extent that many Japanese students have, as is fairly broadly assumed, relatively "weak" oral English skills, the international students did not appear to pay their attention to the proficiency of Japanese students. It was inferred from this analysis that Japanese students' inactivity in EMI courses is evident and it also means that many of them were not able to fully participate in the ELF communication.

\subsection{The lack of spontaneity of Japanese students as L1 speakers in JMI courses}

In Table 1, the item "(2-1) lack of spontaneity of Japanese students” can be identified in both courses. Especially notable is the figure of $8.5 \%$ from international students in JMI courses:

(6) We, international students wish that Japanese students would provide their opinions more spontaneously.

(International student [L2]/JMI)

(7) I am originally a quiet and less active student in my home university in Germany. But in the class with Japanese students, I was often urged to take initiative because everyone was just waiting for someone to start the discussion. (International student [L2]/JMI) 
Some Japanese students are also aware of this observation as indicated by the $2.6 \%$ in "(2-1) lack of spontaneity of Japanese students" in the JMI courses. These students may be afraid to be "aggressive", seeing themselves as reluctant to assert their views in contrast to the way international students are perceived:

(8) Japanese students tend to hesitate to aggressively put into practice what they wish to do. In contrast, international students are the opposite. I have never noticed this before and it was a good opportunity to re-assess the behaviours of ourselves, Japanese people.

(Japanese student [L1]/JMI)

Some Japanese students also perceive this as their own problem as shown by the $2.0 \%$ in "(1-3) lack of spontaneity" in the JMI courses. It is this lack of spontaneity, which may lead to a drive to "improve":

(9) I am not good at expressing my opinion first. Today, I could not say what I wanted to say and would like to improve this in future.

(Japanese student [L1]/JMI)

The data thus indicate that although there is no language barrier in JMI courses, Japanese students tend not to be spontaneous even within their L1 speaker context. Therefore, Japanese students' hesitation to say something cannot entirely be due to their level of linguistic confidence or self-perceived lack of proficiency in language.

In contrast, "(3-1) activeness of international students" is noteworthy in both courses. As stated in the data, international students (Japanese L2 speakers) appear to take the initiative in the group discussions in JMI courses instead of Japanese L1 speakers.

(10) It is always the international students who start the discussion in my group. (International student [L2]/JMI)

(11) During the group discussions, I recognised that international students tend to provide their opinions more often than do Japanese students.

(Japanese student [L1]/JMI)

It can be inferred from the above that Japanese L1 speakers tended to be reserved, while Japanese L2 speakers were leading the discussions in JMI courses. This means that the linguistic level of discussions was not dominated by an L1 speaker standard, but rather, due to the initiative of L2 speakers (international students), the linguistic level was accommodated to L2 speaker level, as we shall see next. 


\subsection{Consideration for the linguistically disadvantaged by Japanese L1 speakers in JMI courses}

It is interesting that the majority of those who are conscious of accommodation skills displayed by Japanese L1 speakers in JMI courses are the Japanese students themselves, with $7.8 \%$ in comparison to $2.6 \%$ for international students (Japanese L2 speakers) in relation to "(4-1) consideration for the linguistically disadvantaged”. What the Japanese L1 speakers did for Japanese L2 speakers seems to occupy Japanese students' mind:

(12) I tried to avoid difficult words. I was always careful with expressions that I use unconsciously.

(Japanese student [L1]/JMI)

(13) During the discussion, I tried to speak a little slowly.

(Japanese student [L1]/JMI)

(14) In this class, I gradually get used to summarise and rephrase what the international students said for sharing better understanding. It is still difficult to explain why some of the expressions and the usages must be so in the Japanese language, which frustrates me. I must expand my own knowledge of Japanese expressions and vocabulary.

(Japanese student [L1]/JMI)

This characteristic of Japanese L1 speakers was noted and appreciated by a Japanese L2 speaker:

(15) When we encountered difficult words, Japanese students kindly explained them thoroughly for us.

(International student [L2]/JMI)

However, the quantitative data show that "(4-1) consideration for the linguistically disadvantaged" was not a special issue for international students: i.e., 0\% in EMI courses and $2.6 \%$ in JMI courses compared with the $7.8 \%$ mentioned above.

\subsection{Rapport building}

Rapport building is listed as one of the pragmatic skills in ELF, according to Taguchi and Ishihara (2018). An indication of rapport-building action appears to include the attitude of "listening to each other". The rate for "(4-2) effective rapport building" was higher in JMI than in EMI courses, and rapport building was attained by listening to each other with a sincere attitude. 
(16) There was an atmosphere that everyone listened to others sincerely. (International student [L2]/JMI)

(17) The discussion was easy to follow because both international and Japanese students tried to speak clearly.

(Japanese student [L1]/JMI)

The opposite example of no rapport building was also found, although there were only a few examples in both courses. The following case indicates that the use of a language which is not shared by all the members can make others feel excluded; thus, equal participation was not achieved:

(18) It was unpleasant when some group members were speaking in their mother tongue, which others in the group do not understand at all. (Japanese student [L1]/JMI)

\section{Discussion}

In the ELF context of this study, it is inferred from the analysis that Japanese students (English L2 speakers) were not able to fully participate in the lingua franca communication, and interactions were mainly managed by non-Japanese members. While in the JLF context, the inclusion of all the members was achieved to a certain extent according to the qualitative analysis in "(4-1) consideration for the linguistically disadvantaged” and “(4-2) effective rapport building”. Under such a condition, a context where rapport is built successfully and there are considerations made for those who are of lower language proficiency level, the spontaneous utterance of participants will be facilitated, regardless of the linguistic level of the participants. The favourable condition for lingua franca communication can be that the equal participation of every member is assured in the shared space and the sense of being included is guaranteed, regardless of the variety in linguistic levels. "The right to speak" is strongly emphasized in the concept of the ownership of English (Norton 1997; Widdowson 1994); therefore, the members' successful rapport building will be the first step for lingua franca construction.

Regarding how actual interaction flows, the data show that taking the initiative in an interaction is not necessarily an L1 speaker role. The initiative was often taken by Japanese L2 speakers in JMI courses and the Japanese L1 speakers' lack of spontaneous attitude was criticized by international students (Japanese L2 speakers). However, the pace and language level of discussion were not dominated by an L1 speaker standard, because Japanese L1 speakers were reserved in the classroom. 
Instead, the international students (Japanese L2 speakers) who took the initiative seem to have determined the pace of group discussions. The attitude of Japanese students in JMI courses may have served as a kind of accommodation strategy. It is important that L1 speakers do not set the standard of the lingua franca communication at their own L1 speaker linguistic level. In addition to Japanese L1 students' reserved attitude in JMI courses, their consideration for the linguistically disadvantaged L2 speakers and the detailed reflections on this by Japanese students as L1 speakers are worth considering. Similar kinds of L1 speaker actions, such as speaking slowly and clearly, choosing simple words, and avoiding idioms, were also reported in Margić (2017) and Rogerson-Revell (2010) as accommodating actions in ELF communication.

Margić (2017) observed that L1 speakers show courtesy to L2 speakers through these accommodating skills and help the interlocutor to hone their English language skills. She argued this might impose an unbalanced burden on L1 speakers through the perception that it is always L1 speakers who need to serve and compromise. In this study, however, no negative tones from Japanese L1 speakers in their consideration for Japanese L2 speakers were observed. One of the data items below, which appeared in "(4-1) consideration for the linguistically disadvantaged”, shows that there is no self-sacrifice in the action of consideration, and this Japanese student is seeking common benefits for both L1 speakers and L2 speakers:

For better communication, it is better not to use difficult terms and expressions even among L1 speakers. It was rather a good occasion to learn to speak in consideration of the understanding of international students. (Japanese student [L1]/JMI)

Communication strategies and accommodation strategies are often focused on in lingua franca research. In ELF, these strategies are considered to cover challenges in proficiency and fluency. Björkman (2011) concluded that management of speech was not more important than one's ability to make use of pragmatic strategies. Her empirical study on EMI with various exchange students in a Swedish university indicated that students with varying degrees of proficiency and fluency could use pragmatic strategies. This finding endorses the phenomenon in the present study in Japanese courses that L1 speakers were not necessarily advantaged in participation in Japanese-language discussions.

The data from this study may contradict L1 speakers' apparent shortcomings in managing ELF, which was previously mentioned above. This study strongly suggests that the situation regarding L1 speakers in lingua franca interaction appears to be very different in JLF when contrasted to ELF. As discussed in Section 7, in JMI courses, the Japanese L1 speakers naturally made attempts to accommodate their L2 peers without having been instructed explicitly in the classrooms. There is a 
conventional perception of Japanese people as adopting a general tradition of ensuring harmony in the group, i.e., being concerned about people around them and trying not to be distinctive. The literature points out that a high context communication pattern, in which not the whole of the message is explicitly expressed by language, often leads to ambiguity and indirectness (Gudykunst 2004; Gudykunst and Nishida 1993; Hall 1976; Lim 2003), and that in a collectivist culture (Hofstede 1991), harmony within a group is of great importance (Sugimoto 2014; Wierzbicka 1997). The maintenance of harmony in ELF communication in collectivist cultures is also emphasized in other studies (see e.g. Henderson 2005; Rogerson-Revell 2010; Sweeney and Hua 2010). The findings of the verbal behaviours of Japanese students in JMI courses in this study certainly indicate communication patterns often associated with a collectivist culture. However, caution must be exercised in this kind of interpretation, which tends to assume that some national cultures can be designated as uniformly collectivist. Whatever the merits of such interpretations might have been in the past, it is evident that national groups are changing in the present, and such interpretations are criticized as "essentialist." It is argued that they focus on emphasizing how a national group is uniform and different from others (Buhagiar et al. 2018) and in particular how some national groups differ from western culture (Kubota 2008). It is crucial that we guard against over-applying this kind of interpretation and avoid essentializing the research participants.

The major point of this study is to shed light on the role of L1 speakers in the coconstruction of a lingua franca in any language. What this study shows is that rapport building and consideration for the linguistically disadvantaged are not simply skills and strategies to be acquired and learned, but they are a matter of attitude and mindset, as Wang and Jenkins (2016) also emphasize - attitude plays an important role in the achievement of intelligibility. Thus ELF education which includes L1 users barely fits into the existing EFL framework, that is, EFL and ELF are fundamentally different, especially in their educational goals. The framework shown in Table 2 is proposed from the findings of this study.

Taking this perspective and leaving aside the EFL or JFL framework, it can be said that most international students in both EMI and JMI courses in this study managed the common languages well and successfully transformed themselves into "speakers" or "users" rather than language learners (Kim et al. 2014: 454). Furthermore, in both courses it was Japanese students who showed their concerns about their own language ability and also paid strong attention to the Japanese language skills of international students in JMI courses. For success in a lingua franca setting, this study suggests that it is important that L2 speakers become "users," free from the anxieties and concerns with their own linguistic competence, and that all the members feel able to equally participate in the community. 
Table 2: Comparison between English as a foreign language (EFL) and English as a lingua franca (ELF).

\begin{tabular}{lll}
\hline & EFL & ELF \\
\hline L1 speakers & $\begin{array}{l}\text { Not included except for instructors/ } \\
\text { teaching assistants }\end{array}$ & Included \\
\hline Participants & Language learners & $\begin{array}{l}\text { Language speakers (Kim et al. 2014) } \\
\text { Language users }\end{array}$ \\
\hline $\begin{array}{l}\text { Educational } \\
\text { goals }\end{array}$ & L1 speaker norm/L1 speaker model & $\begin{array}{l}\text { Successful intercultural communication } \\
\text { Jenkins 2015) } \\
\end{array}$ \\
\hline
\end{tabular}

Given that in ELF, JLF, or indeed any other language as a lingua franca, the goals are intelligibility and intercultural communication, it is education focussing on attitude and mindset that is needed. Education in a lingua franca will not fit in the conventional foreign language education framework which targets L2 learners only. An educational framework for lingua franca communication which includes "both L1 speakers and L2 speakers" will need to focus on intercultural education to develop attitude and mindset rather than focussing solely on linguistic and pragmatic skills. This will also overlap with education fostering an "intercultural speaker," who can act as a mediator/negotiator in a transcultural space Byram (1997, 2008, 2021), which is also seen as pedagogic necessity in relation to ELF specifically by Baker (2015a). Byram (2008) also emphasizes that although being $\mathrm{bi} /$ multicultural is a consequence of living in certain situations, people become intercultural - with particular attitudes, mindset and skills different from those who are bi/multicultural - as a consequence of being a learner under the direction of a teacher. This implies that to foster the development of successful "lingua franca users", it is not enough to establish a multicultural context: an effort to create an educational intervention is needed.

\section{Conclusions and future implications}

In the university where this study was conducted, EMI multicultural courses were initially created for international exchange students whose language skills were deemed to be not enough for academic studies in Japanese and who needed lectures conducted in English besides beginners-intermediate level Japanese language courses. The EMI courses were also open to Japanese students and were 
regarded as good opportunities for them to improve their English skills. However, in reality, it was difficult for them to participate, with a similar EMI undergraduate course in another Japanese university described as "the participants left out in the periphery" (Iino 2019), which according to Iino reflects a lack of analysis of the "E" of EMI in the Japanese context from an ELF perspective. EMI is often promoted for nationally led global education policy but not in consideration of such reality in the classrooms. It will be the role of ELF research to shed light on the inclusiveness of ELF interactions and thus contribute to a greater understanding of the nature of EMI opportunities from an ELF perspective.

The effect of JMI in multicultural courses became evident, as well. D'Angelo (2018) points out that ELF research shows how Japanese university students can better cope with the reality of sharing an interactive, discussion-based classroom with an internationally diverse student population. This study has shown that Japanese students had this same learning experience in JMI courses and gained inspiration for future language learning (i.e. English learning) in JMI courses.

The analysis of the data demonstrates the potential of multicultural courses where both L1 speakers and L2 speakers study together to foster lingua franca users via a different pedagogical framework from that of conventional foreign language education. In a lingua franca framework, the significance of cognitive and psychological aspects of communication was highlighted. Both L1 speakers and advanced level L2 speakers need to learn how to create a space where all members are included and learn how to adjust their language for those who are linguistically at lower levels. It is important that all participants aim to achieve intercultural communication as a common goal. This means that participants, whether they are L1 speakers or L2 speakers of the language, need to be aware how to suspend their own cultural criteria and to act interculturally (Byram 2008) rather than attempt to communicate in a "culture-free" mode. Intercultural Communicative Competence (ICC) described by Byram (1997, 2008, 2021) and Intercultural Awareness (ICA) described by Baker (2015a) will be the significant characters of lingua franca pedagogy (Baker 2015a).

Finally, the research limitations of this study need to be declared. An ethnographic investigation using a qualitative research design was deemed to be most suitable as stated earlier, but the influence of the researcher's participation and the specificity of the context cannot be totally avoided. In addition, the characteristics of multicultural courses are said to vary according to the institution, the ratio of international and Japanese students and their academic skills. Therefore, there might be cases where similar results are not produced in other institutions, even in Japan. Although the implications from this research are valuable, it only sheds light on one of the several aspects of lingua franca education in multicultural courses. Further empirical research in multicultural courses such as one which 
includes explicit induction of attitude and mindset needs to be conducted to investigate the issues further.

Acknowledgments: I would like to express my gratitude to Professor Michael Byram for the valuable comments on earlier versions of this manuscript and continuous encouragement since my doctoral studies. I would also like to thank the editors and the reviewers for their insightful comments and suggestions. I also wish to extend my thanks to the students who participated in this study.

Research funding: This work was supported by JSPS KAKENHI Grant Nos. JP15K02626, JP18K00775, and Publication Support Grants of Hokkaido University, under the programme for promoting the enhancement of research universities, MEXT.

Disclosure statement: No potential conflict of interest was reported by the author.

\section{References}

ACTFL 2012 (American Council on the Teaching of Foreign Languages). ACTFL proficiency guidelines 2012. Alexandria, VA: ACTFL. https://www.actfl.org/sites/default/files/guidelines/ ACTFLProficiencyGuidelines2012.pdf (accessed 20 December 2020).

Baker, Will. 2015a. Culture and complexity through English as a lingua franca: Rethinking competences and pedagogy in ELF. Journal of English as a Lingua Franca 4(1). 9-30.

Baker, Will. 2015b. Culture and identity through English as a lingua franca. Berlin \& Hong Kong: Walter de Gruyter.

Björkman, Beyza. 2011. Pragmatic strategies in English as an academic lingua franca: Ways of achieving communicative effectiveness? Journal of Pragmatics 43(4). 950-964.

Borghetti, Claudia \& Ana Beaven. 2017. Lingua francas and learning mobility: Reflections on students' attitudes and beliefs towards language learning and use. International Journal of Applied Linguistics 27(1). 221-241.

Brinkmann, Svend \& Steinar Kvale. 2018. Doing interviews, 2nd edn. London \& Thousand Oaks, CA: Sage Publications.

Buhagiar, Luke, Gordon Summut, Alessia Rochira \& Sergio Salvatore. 2018. There's no such thing as a good Arab: Cultural essentialism and its functions concerning the integration of Arabs in Europe. Culture \& Psychology 24(4). 560-576.

Byram, Michael. 1997. Teaching and assessing intercultural communicative competence. Clevedon: Multilingual Matters.

Byram, Michael. 2008. From foreign language education to education for intercultural citizenship: Essays and reflections. Clevedon: Multilingual Matters.

Byram, Michael. 2021. Teaching and assessing intercultural communicative competence revisited, 2nd edn. Bristol: Multilingual Matters.

Campbell, Donald, Peansiri Ekniyom, Anjum Haque \& Larry Smith. 1983. English in international settings: Problems and their causes. In Larry Smith (ed.), Readings in English as an international language, 35-47. Oxford \& New York: Pergamon Press. 
Council of Europe. 2001. Common European framework of reference for languages: Learning, teaching, assessment. Cambridge: Cambridge University Press.

Cutrone, Pino \& Siewkee Beh. 2018. Investigating the effects of task-based language teaching on Japanese EFL learners' willingness to communicate. Journal of Asia TEFL 15(3). 566-589.

D’Angelo, James. 2018. The status of ELF in Japan. In Jennifer Jenkins, Will Baker \& Martin Dewey (eds.), The Routledge handbook of English as a lingua franca, 101-112. Abington \& New York: Routledge.

Effiong, Okon. 2016. Getting them speaking: Classroom social factors and foreign language anxiety. TESOL Journal 7(1). 132-161.

e-Stat. 2020. Zairyu Gaikokujin Toukei [The statistics of foreign residents]. Tokyo: e-Stat. https://www.e-stat.go.jp/stat-search/files?page=/\&layout=datalist\&toukei= 00250012\&stat $=0000010 / 8034 \&$ cycle $=/ \&$ (accessed 20 December 2020).

Firth, Alan. 1996. The discursive accomplishment of normality: On "lingua franca" English and conversation analysis. Journal of Pragmatics 26(2). 237-259.

Flick, Uwe. 2018. Designing qualitative research, 2nd edn. London \& Thousand Oaks, CA: Sage Publications.

Gnutzmann, Claus. 2017. Lingua franca. In Michael Byram \& Adelheid Hu (eds.), Routledge encyclopedia of language teaching and learning, 2nd edn., 413-416. Avingdon \& New York: Routledge.

Gudykunst, William. 2004. Bridging differences. Effective intergroup communication, 4th edn. Thousand Oaks, CA: Sage Publications.

Gudykunst, William \& Tsukasa Nishida. 1993. Interpersonal and intergroup communication in Japan and the United States. In William Gudykunst (ed.), Communication in Japan and the United States, 149-214. Albany: State University of New York Press.

Haberland, Hartmut. 2011. Ownership and maintenance of a language in transnational use: Should we leave our lingua franca alone? Journal of Pragmatics 43(4). 937-949.

Hall, Edward. 1976. Beyond culture. New York \& London: Anchor Books.

Henderson, Jane. 2005. Language diversity in international management teams. International Studies of Management and Organization 35(1). 66-82.

Hofstede, Geert. 1991. Cultures and organizations. London: McGrowhill.

Hokkaido University. 2019. Hokkaido University guidebook 2019-2020. Sapporo: Hokkaido University. https://www.global.hokudai.ac.jp/wp-content/uploads/2019/08/ huguidebook2019-2020-web-1.pdf (accessed 20 December 2020).

Hokkaido University. 2020. Hokkaido University campus initiative. Sapporo: Hokkaido University. https://www.global.hokudai.ac.jp/about/hokkaido-universal-campus-initiative-huci/ (accessed 20 December 2020).

lino, Masakazu. 2019. EMI (English-medium instruction) in Japanese higher education: A paradoxical space for global and local sociolinguistic habitats. In Kumiko Murata (ed.), English-medium instruction from an English as a lingua franca perspective: Exploring the higher education context, 78-95. Abington \& New York: Routledge.

Immigration Services Agency of Japan. 2003. Heisei 15 nenban "Shutsu Nyukoku Kanri” [The statistics of immigration control in 2003]. Tokyo: Immigration Services Agency of Japan. https://www.moj.go.jp/isa/policies/policies/nyukan_nyuhaku_index.html (accessed 20 December 2020).

JASSO (Japan Student Services Organization). 2019. Student guide to Japan 2019-2020. Tokyo: JASSO. https://www.jasso.go.jp/en/study_j/_icsFiles/afieldfile/2019/05/16/sgtj_2019_e. pdf (accessed 20 December 2020). 
JASSO (Japan Student Services Organization). 2020. Result of an annual survey of international students in Japan 2019. Tokyo: JASSO. https://www.studyinJapan.go.jp/en/_mt/2020/08/ date2019z_e.pdf (accessed 20 December 2020).

Jenkins, Jennifer. 2007. English as a lingua franca: Attitude and identity. Oxford: Oxford University Press.

Jenkins, Jennifer. 2011. Accommodating (to) ELF in the international university. Journal of Pragmatics 43(4). 926-936.

Jenkins, Jennifer. 2012. English as a lingua franca from the classroom to the classroom. ELT Journal 66(4). 486-494.

Jenkins, Jennifer. 2015. Global Englishes: A resource book for students. London \& New York: Routledge.

Kim, Jeongyeon, Bradley Tatar \& Jinsook Choi. 2014. Emerging culture of English-medium instruction in Korea: Experiences of Korean and international students. Language and Intercultural Communication 14(4). 441-459.

Kirkpatrick, Andy. 2014. Teaching English in Asia in non-Anglo cultural contexts: Principles of the “lingua franca approach”. In Roby Marlina \& Ram Ashish Giri (eds.), The pedagogy of English as an international language: Perspectives from scholars, teachers, and students, 23-34. New York \& London: Springer.

Kubota, Ryuko. 2008. Critical approaches to teaching Japanese language and culture. In Junko Mori \& Amy Ohta (eds.), Japanese applied linguistics: Discourse and social perspectives, 327-352. London \& New York: Continuum.

Lim, Tae-Seop. 2003. Language and verbal communication across cultures. In William Gudykunst (ed.), Cross-cultural and intercultural communication, 53-71. Thousand Oaks, CA, London \& New Delhi: Sage Publications.

Margić, Branka. 2017. Communication courtesy or condescension? Linguistic accommodation of native to non-native speakers of English. Journal of English as a Lingua Franca 6(1). 29-55.

Matsuta, Ken, Mary Byrd \& Jean Ware. 2001. Classroom use of critical thinking skills: Student and teacher surveys. Kokusai Kirisutokyo Daigaku Gakuhou 1-A Kyouiku Kenkyu [Educational Studies: International Christian University] 43. 199-217.

MEXT (Ministry of Education, Culture, Sports, Science and Technology - Japan). 2008. "Ryugakusei Ukeire Sanjyumanin Keikaku" Kosshi [Outline of plan for 300,000 exchange students]. Tokyo: MEXT. https://www.mext.go.jp/a_menu/koutou/ryugaku/_icsFiles/ afieldfile/2019/09/18/1420758_001.pdf (accessed 20 December 2020).

MEXT. 2020a. Ryugakusei Ukeire Jyumanin Keikaku [Plan for 100,000 exchange students]. Tokyo: MEXT. https://www.mext.go.jp/b_menu/hakusho/html/others/detail/1318576.htm (accessed 20 December 2020).

MEXT. 2020b. Top global University Japan. Tokyo: MEXT. https://tgu.mext.go.jp/en/about/index. html (accessed 20 December 2020).

Miles, Matthew, Michael Huberman \& Johnny Saldaña. 2020. Qualitative data analysis: A methods sourcebook, 4th edn Thousand Oaks, CA: Sage Publications.

Norton, Bonny. 1997. Language, identity, and the ownership of English. TESOL Quarterly 31(3). 409-429.

Olson, Tom. 2000. Numbers, narratives, and nursing history. The Social Science Journal 37(1). 137-144.

Philipson, Robert. 1992. Linguistic imperialism. Oxford: Oxford University Press.

Philipson, Robert. 2003. English-only Europe? Challenging language policy. London: Routledge. 
Rogerson-Revell, Pamela. 2010. “Can you spell that for us nonnative speakers?” Accommodation strategies in international business meetings. Journal of Business Communication 47(4). 432-454.

Sakamoto, Toshiko. 2013. Ibunka Kouryu Jyugyou kara Kokunai Gakusei wa Nani o Manandeiruka [What do local Japanese students learn in multicultural courses?]. Ritsumeikan Gengobunka Kenkyu [Ritumeikan Language \& Culture Research] 24(3). 143-157.

Sandelowski, Margarete. 2001. Focus on research methods: Real qualitative researchers do not count: The use of numbers in qualitative research. Research in Nursing and Health 24(3). 230-240.

Sato, Yuriko. 2011. Nihon eno Tanki Ryugaku no Niizu to Kadai ni kansuru Kousatsu: Tanki Ryugakusei Chousa Kaitou no Chiikibetsu Kikanbetsu Kadaibetsu Bunseki kara [The needs and issues of short-term study abroad to Japan: The survey result breakdowns on short-term international students by areas, institutions and issues]. Ryugakusei Kyoiku [International student education] 16. 12-24.

Seidlhofer, Barbara. 2011. Understanding English as a lingua franca. Oxford: Oxford University.

Seidlhofer, Barbara. 2012. Anglophone-centric attitudes and the globalization of English. Journal of English as a Lingua Franca 1(2). 393-407.

Smith, Larry. 1976. English as an international auxiliary language. RELC Journal 7(2). 38-42.

Smith, Larry. 1983. English as an international language: No room for linguistic chauvinism. In Larry Smith (ed.), Readings in English as an international language, 7-11. Oxford \& New York: Pergamon Press.

Subtirelu, Nicholas \& Stephanie Lindemann. 2016. Teaching first language speakers to communicate across linguistic difference: Addressing attitudes, comprehension, and strategies. Applied Linguistics 37(6). 765-783.

Sugimoto, Yoshio. 2014. An introduction to Japanese society, 4th edn. Melbourne: Cambridge University Press.

Sweeney, Emma \& Zhu Hua. 2010. Accommodating toward your audience: Do native speakers of English know how to accommodate their communication strategies toward nonnative speakers of English? Journal of Business Communication 47(4). 477-504.

Taguchi, Naoko \& Noriko Ishihara. 2018. The pragmatics of English as a lingua franca: Research and pedagogy in the era of globalization. Annual Review of Applied Linguistics 38. 80-101.

Talandis, Gerald \& Michael Stout. 2015. Getting EFL students to speak: An action research approach. ELT Journal 69(1). 11-25.

Wang, Ying \& Jennifer Jenkins. 2016. "Nativeness" and "intelligibility”: Impacts of intercultural experience through English as a lingua franca on Chinese speakers' language attitudes. Chinese Journal of Applied Linguistics 39(1). 38-58.

Watanabe, Masahito, Jun Kaneyama, Mami Harada \& Shinobu Suzuki. 2017. Kokusai Koryu Kamoku no Kyoiku ni kansuru Chousa [Survey report on arts and science courses in English]. In Shinobu Suzuki \& Noriko Masuda (eds.), Zengaku Kyoiku Gaikokugo no Genjyo to Kadai [Issues on foreign language education in general education], 55-63. Sapporo: Research Faculty of Media and Communication, Hokkaido University.

Widdowson, Henry. 1994. The ownership of English. TESOL Quarterly 28(2). 377-389.

Widdowson, Henry. 2018. Historical perspectives on ELF. In Jennifer Jenkins, Will Baker \& Martin Dewey (eds.), The Routledge handbook of English as a Lingua Franca, 101-112. Abington \& New York: Routledge.

Wierzbicka, Anna. 1997. Understanding cultures through their key words. New York \& Oxford: Oxford University Press. 
Yamada, Etsuko. 2019a. Tabunkakurasu niokeru Nihon no Gakusei no Gengokoudou:

Shiyougengo no Kotonaru Kurasu no Hikaku kara [Verbal behaviors of Japanese students in multicultural classrooms: A comparative study of courses in different languages of instruction]. Kotokyoiku Journal: Kotokyoiku to Shogaigakushu [Journal of Higher Education and Lifelong Learning] 26. 11-23.

Yamada, Etsuko. 2019b. Ryugakusei to Nihon no Gakusei ga Tomonimanabu Tabunkakurasu niokeru Ringa Furanka no Kochiku [Co-construction of a lingua franca by international students and local Japanese students in multicultural courses]. In The 25th Princeton Japanese Pedagogy Forum Proceedings, 11-12 May 2019, 1-12. Princeton: Princeton University https://pjpf.princeton.edu/25th-princeton-japanese-pedagogy-forum (accessed 20 December 2020).

\section{Bionote}

\section{Etsuko Yamada}

Research Faculty of Media and Communication, Hokkaido University, Sapporo, Hokkaido, Japan etsukoyamada91@gmail.com

https://orcid.org/0000-0002-7673-5615

Etsuko Yamada is Associate Professor at Hokkaido University, Japan. She teaches intercultural education for international and Japanese students. Previously, she taught Japanese in Germany and the UK. She holds a PhD in Education from the University of Durham, UK. Her main research interests lie in intercultural education and critical cultural awareness. 